PREFACE

\section{Facial Trauma}

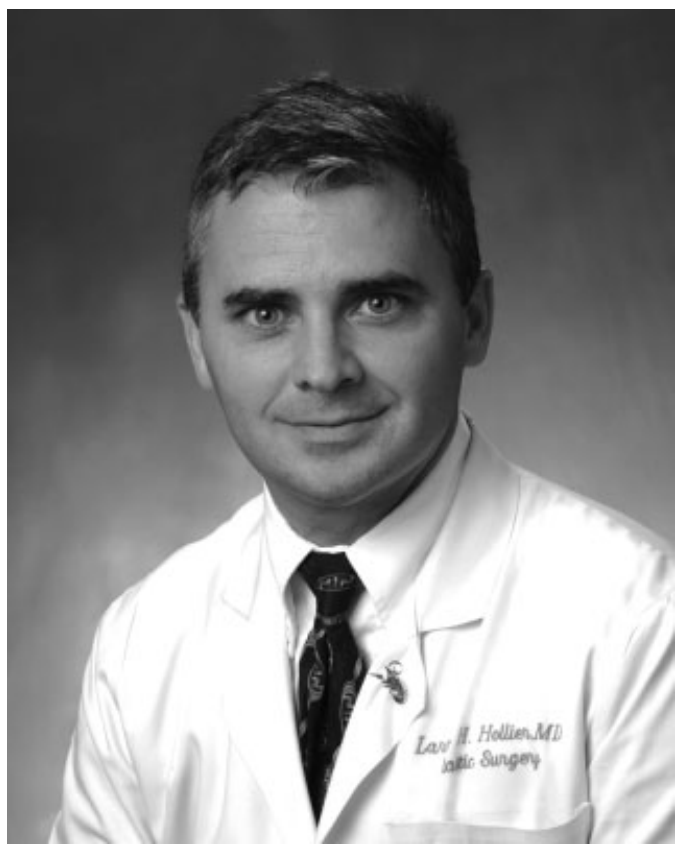

$\mathrm{I}_{\mathrm{t}}$ is with great pleasure that I introduce this issue of Seminars in Plastic Surgery focused on the treatment of facial trauma. This is one of my areas of particular interest and focus. I have long believed that too much of the literature in this area has focused on old paradigms. Over and over, the mantra of "anatomically reduce and stably fixate" is repeated. Though this is well and good, there are things that work and things that don't. Technologic improvements in both imaging and fixation have changed the way we treat facial trauma. Each of the articles in this issue focuses on practical aspects of managing the most common facial injuries. It is my hope that readers will learn practical ideas that they can translate into immediate improvements in the care of their patients.
Larry H. Hollier, Jr., M.D. ${ }^{1,2}$

Editor-in-Chief

\footnotetext{
${ }^{1}$ Department of Dermatology, Baylor College of Medicine; ${ }^{2}$ Ben Taub General Hospital, Houston, Texas.

Address for correspondence and reprint requests: Larry H. Hollier, Jr., M.D., Chief of Service, Ben Taub General Hospital, 1709 Dryden, Suite 1600, Houston, TX 77030.

Facial Trauma; Guest Editor, Larry H. Hollier, Jr., M.D.
}

Semin Plast Surg 2010;24:337-338. Copyright (C) 2010 by Thieme Medical Publishers, Inc., 333 Seventh Avenue, New York, NY 10001, USA. Tel: +1(212) 584-4662.

DOI: http://dx.doi.org/10.1055/s-0030-1269762.

ISSN 1535-2188. 